\title{
The effects of Soil-Structure Interaction on a reinforced concrete
}

\section{viaduct}

\author{
S. Grange* ${ }^{*}$ L. Botrugno ${ }^{\dagger}$, P. Kotronis ${ }^{\ddagger}$, C. Tamagnini ${ }^{\dagger}$ \\ Laboratoire 3S-R (Sols, Solides, Structures-Risques) UJF/INPG/CNRS UMR 5521, Grenoble \\ Institut de Recherche en Génie Civil et Mécanique (GeM), UMR CNRS 6183, Ecole Centrale de Nantes \\ Dipartimento di Ingegneria Civile e Ambientale, Università degli Studi di Perugia
}

\section{SUMMARY}

This paper presents a numerical strategy to model a three-piers viaduct made of prestressed concrete. The viaduct was tested pseudodynamically in ELSA laboratory (JRC Ispra, Italy). During the experimental campaign, only the three piers where tested, whereas the behaviour of the deck was simulated using the finite element method. The first part of the paper presents a numerical model of the viaduct based on Timoshenko multifiber beam elements and non linear constitutive laws. Comparisons

\footnotetext{
${ }^{*}$ Correspondence to: Laboratoire 3S-R (Sols, Solides, Structures-Risques) UJF/INPG/CNRS UMR 5521 Domaine Universitaire BP 53, 38041 Grenoble cedex 9, France 
with the experimental results show the good performance of the approach. In the second part, a parametric study is carried out showing the influence of Soil-Structure Interaction (SSI). Various types of soils are considered using a recently developed macro-element representing a rigid shallow foundation. The macro-element is suitable for dynamic (seismic) loadings and it takes into account the plasticity of the soil, the uplift of the foundation, $P-\theta$ effects and the radiative damping. Finally, the numerical results are compared with the ones coming from a classical engineering approach using linear elastic springs at the base of the piers. This comparison shows that SSI is a complex phenomenon inducing displacements and internal forces in the structure that are difficult to predict with the linear approach. Based on the results obtained in this paper, it seems now possible to use this approach to investigate numerically the behaviour of a wider variety of configurations. Copyright (c) 2002 John Wiley \& Sons, Ltd.

KEY WORDS: Soil-Structure interaction; foundation; macro-element; Timoshenko beam; viaduct.

\section{INTRODUCTION}

In civil engineering, boundary conditions have to be correctly modelled in order to reproduce numerically the non linear behaviour of a structure. Soil-Structure Interaction (SSI) can not be neglected. This is particularly true for slender structures like tall buildings or bridge piers. Their behaviour is different whether the structure is on a solid rock or on a soft soil.

However, simulating SSI often necessitates the use of detailed and complex 3D finite element models for the soil and the structure, leading to a great number of degrees of freedom and thus to significant computational costs. This is the reason why various simplified modelling strategies have recently been developed. Multifiber beam elements coupled with non-linear constitutive laws allow reproducing the non linear behaviour of the structure. The "macro- 
element" approach helps reproducing the non linear behaviour of the foundations considering material and/or geometric non linearities.

This work deals with a simplified numerical strategy based on multifiber beams and macroelements to investigate the effects of SSI on a reinforced concrete viaduct. The three-piers viaduct made of prestressed concrete was tested experimentally in ELSA laboratory (JRC Ispra, Italy, [22]). The tests were pseudodynamic, i.e. only the three piers were tested. As for the deck, it was simulated using the finite element code Cast3M [2]. During the experiments, the three viaduct piers were fixed at the base (both displacements and rotations are prevented). The article is divided in the two following parts:

- Part I: The viaduct is considered fixed at its base. It is simulated using multifiber Timoshenko beams [16], [18] and non linear constitutive laws based on damage mechanics [17] and plasticity [19]. Comparison with experimental results shows the performance of the approach.

- Part II: The influence of SSI is studied using a recently developed macro-element taking into account the inelastic behaviour of the soil, the uplift of the foundation, $P-\theta$ effects and the radiative damping [11], [12], [13], [14], [15]. The results of a classical engineering approach are finally provided, using linear elastic springs at the base of the piers having an equivalent initial stiffness calibrated using an energy criterion. A comparison of the two approaches shows clearly the advantages of the new macro-element approach. 
A 1:2.5 scaled viaduct was recently tested pseudo-dynamically in ELSA (JRC Ispra) (Fig. 1, 4 S. GRANGE, L. BOTRUGNO, P. KOTRONIS, C. TAMAGNINI

[22]). This kind of hybrid experiment allows testing only a part of the structure, while the rest 2. PART I: MODELING OF THE PSEUDO-DYNAMIC TEST

is simulated with a finite element code. Thus, only the three piers fixed at their bases were tested, the deck being simulated with the element finite code Cast3M [2]. During the test, the interaction between the piers and the deck was calculated in real time by numerically integrating the dynamic equations of motion in time. Inertial forces were calculated and imposed to the model piers by applying the adequate displacements.

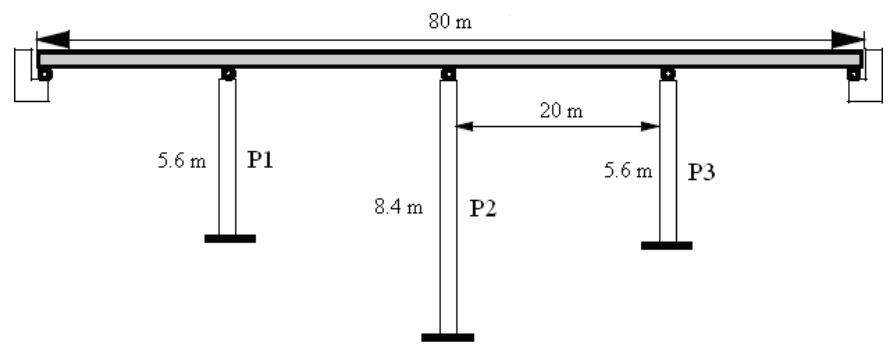

Figure 1. Viaduct: plan view of the tested viaduct in Ispra, (scale 1:2.5) [22].

Details of the deck and piers are given (scaled) in the elevation and section plans of figures 2(a) and 2(b). Piers are made of reinforced concrete and present a hollow rectangular section shape. The deck is composed of hollow "voussoirs" made of prestressed concrete. Its behaviour can thus be considered linear. Details of the geometrical characteristics of the section are given in Table I. 
(a)

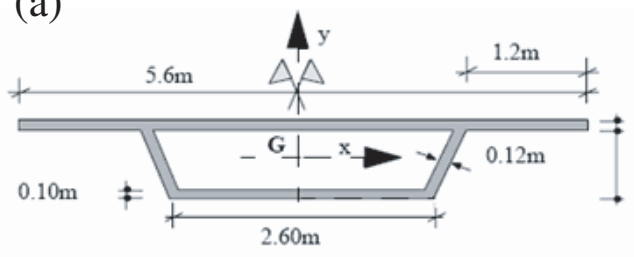

(b)

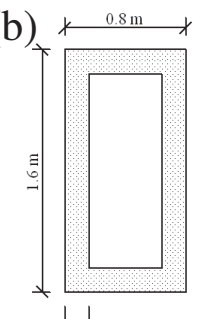

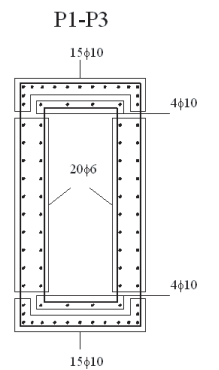

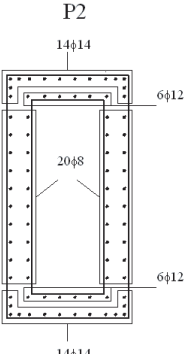

$14 \phi 14$

Figure 2. Viaduct: (a) scheme of the deck (modelled with Cast3M during the experiments), (b) scheme of the piers (scale 1:2.5).

Table I. Viaduct: geometrical characteristics of deck cross section.

\begin{tabular}{cccc}
$A\left(m^{2}\right)$ & $I x\left(m^{4}\right)$ & $I y\left(m^{4}\right)$ & $J\left(m^{4}\right)$ \\
1.11 & 0.13 & 2.26 & 2.39 \\
\hline
\end{tabular}

\subsection{Finite element mesh}

A finite element model using multifiber beams and concentrated masses is chosen to reproduce the structure (Fig. 3). The mass and rotational inertia details are given in Table II.

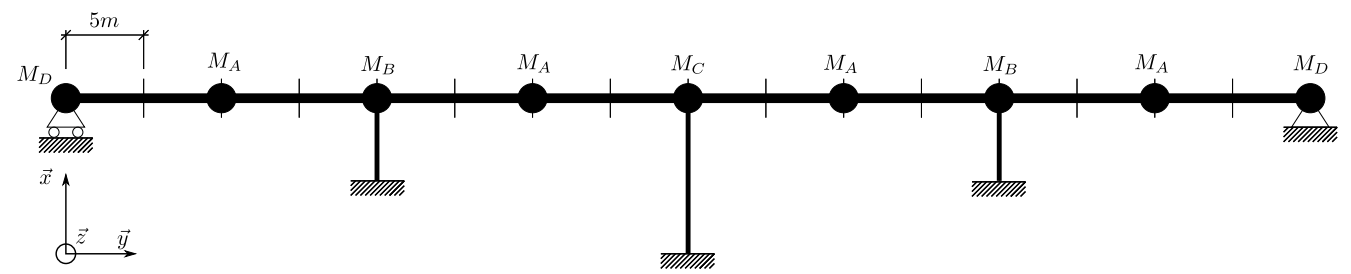

Figure 3. Viaduct: model using multifiber beam elements and concentrated masses.

Non-linear Timoshenko multifiber beam elements are used to reproduce the behaviour of the piers, see Refs. [16] and [18]. Six elements are used for the piers P1 and P3 and nine elements 
Table II. Viaduct: masses and rotational inertia.

\begin{tabular}{cccc}
\hline & Mass $M(k g)$ & Rotational inertia $I_{x}\left(\mathrm{~kg} \cdot \mathrm{m}^{2}\right)$ & Rotational inertia $I_{z}\left(\mathrm{~kg} \cdot \mathrm{m}^{2}\right)$ \\
\hline$M_{A}$ & 27.5 & 285 & 234 \\
$M_{B}$ & 32 & 287 & 271 \\
$M_{C}$ & 34 & 288 & 322 \\
$M_{D}$ & 13.75 & 143 & 117 \\
\hline
\end{tabular}

for the pier P2. Mesh is refined at the base of the piers where damage tends to be concentrated (Fig. 4). 40 concrete fibers and 80 steel fibers (representing the reinforcement bars at their actual position) are used in each section. Details of the fibers used into the section for the piers P1-P3 and P2 are given respectively in Fig. 4 and in Ref. [1]. The deck being made of prestressed concrete, its behaviour is assumed linear and it is discretised using linear beam elements. Calculations are made with FEDEASLab, a finite element MATLAB toolbox [9].

\subsection{Material parameters}

Constitutive model for concrete under cyclic loading ought to take into account some observed phenomena such as decrease in material stiffness due to cracking, stiffness recovery which occurs at crack closure and inelastic strains concomitant to damage. To simulate this behaviour we use a damage model with two scalars variables, one in compression and one in tension [17]. Unilateral effect and stiffness recovery (damage deactivation) are also included. Inelastic strains are taken into account thanks to an isotropic tensor (figure 5). The total strain is given by: 
Pier P2

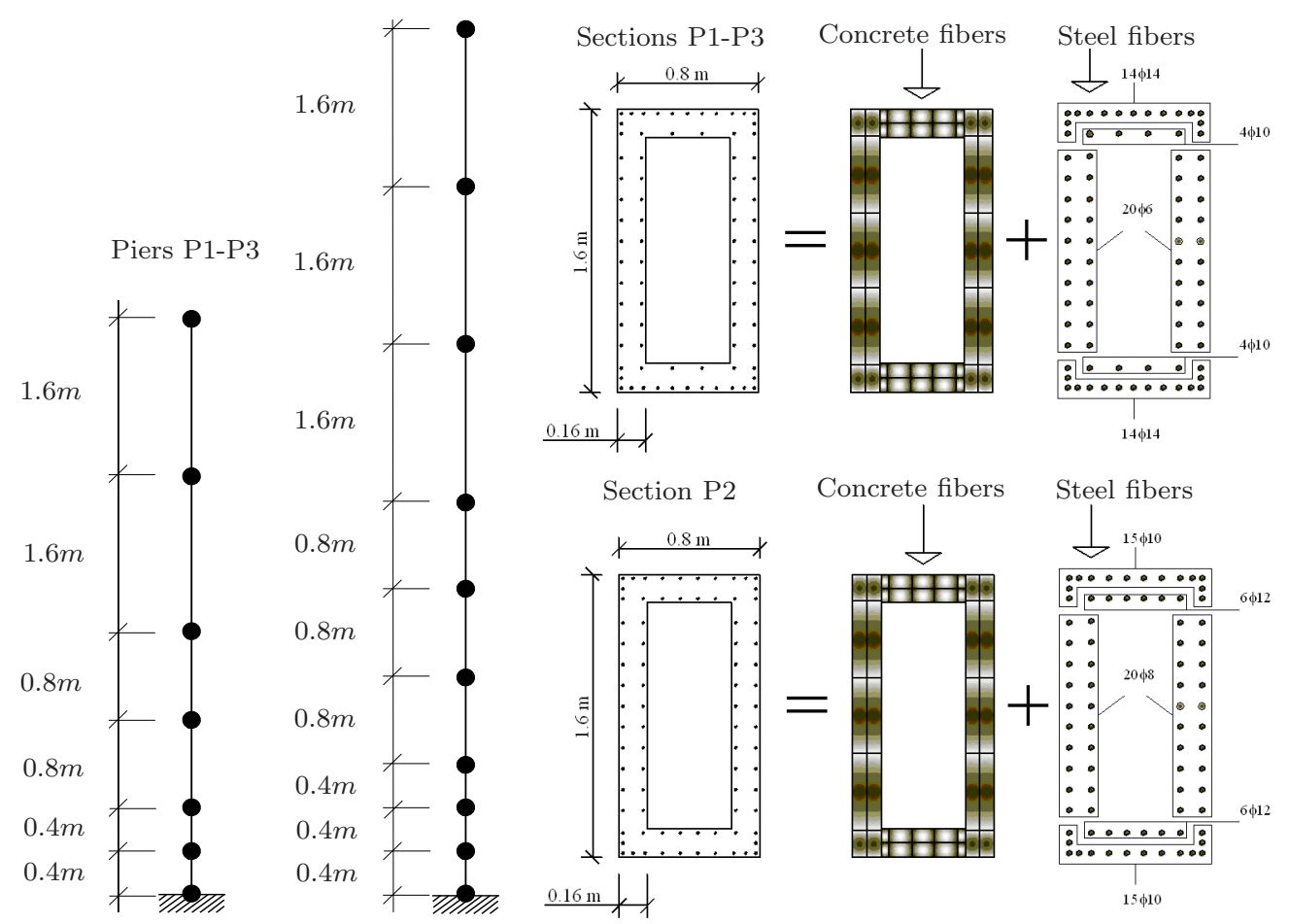

Figure 4. Viaduct: details of the multifiber beam element mesh (piers P1, P2 et P3).

$$
\left\{\begin{array}{l}
\epsilon=\epsilon^{\mathbf{e}}+\epsilon^{\mathbf{i n}} \\
\epsilon^{\mathbf{e}}=\frac{\langle\sigma\rangle_{+}}{E\left(1-D_{1}\right)}+\frac{\langle\sigma\rangle_{-}}{E\left(1-D_{2}\right)}+\frac{\nu}{E}(\sigma-\operatorname{Tr}(\sigma) \mathbf{I}) \\
\epsilon^{\text {in }}=\frac{\beta_{1} D_{1}}{E\left(1-D_{1}\right)} \frac{\partial f(\sigma)}{\partial \sigma}+\frac{\beta_{2} D_{2}}{E\left(1-D_{2}\right)} \mathbf{I}
\end{array}\right.
$$

where

$$
\left\{\begin{array}{l}
\operatorname{Tr}(\sigma) \in[0,+\infty) \rightarrow \frac{\partial f(\sigma)}{\partial \sigma}=\mathbf{I} \\
\operatorname{Tr}(\sigma) \in\left[-\sigma_{f}, 0\right] \rightarrow \frac{\partial f(\sigma)}{\partial \sigma}=\left(1-\frac{\operatorname{Tr}(\sigma)}{\sigma_{f}}\right) \mathbf{I} \\
\operatorname{Tr}(\sigma) \in\left(-\infty,-\sigma_{f}\right] \rightarrow \frac{\partial f(\sigma)}{\partial \sigma}=0 . \mathbf{I}
\end{array}\right.
$$


with $\epsilon^{\mathbf{e}}$ the elastic strains, $\epsilon^{\mathbf{i n}}$ the inelastic strains and $\sigma$ the stress tensor. I denotes the unit tensor, $\operatorname{Tr}(\sigma)=\sigma_{i j}, f$ is the crack closure function and $\sigma_{f}$ the crack closure stress. $\langle.\rangle_{+}$ denotes the positive and $\langle.\rangle_{-}$the negative part of the tensor. $E$ is the initial Young's modulus and $\nu$ the Poisson ratio. $D_{1}$ and $D_{2}$ are respectively the damage variables for tension and compression, $\beta_{1}$ and $\beta_{2}$ are material constants. Damage criteria are expressed as $f_{i}=Y_{i}-Z_{i}$ ( $i=1$ for tension or 2 for compression, $Y_{i}$ is the associated force to the damage variable $Z_{i}$ and $Z_{i}$ a threshold dependent on the hardening variables). The evolution laws for the damage variables $Z_{i}$ are written as:

$$
D_{i}=1-\frac{1}{1+\left[A_{i}\left(Y_{i}-Y_{0 i}\right)\right]^{B_{i}}}
$$

where $Y_{0 i}$ is the initial elastic threshold $\left(Y_{0 i}=Z_{i}\left(D_{i}=0\right)\right.$ and $A_{i}, B_{i}$ material constants. For the calculations presented hereafter the uniaxial version of the damage model is used (shear is considered linear). Figure 5 gives the stress-strain response of the model for an uniaxial tension-compression.

A modified version of the classical Menegotto-Pinto model [19] with an isotropic hardening is used for steel. $f_{y}$ and $f_{s u}$ are the yield and the maximum stresses for the steel associated to the strains $\epsilon_{s h}$ and $\epsilon_{s u}$, respectively. Figure 6 gives the stress-strain response of the model.

It is worth noting that as the tests are pseudo-dynamic, the damping coefficient adopted in the numerical simulations has to be small. A $0.5 \%$ coefficient is used, calibrated on the $1^{\text {st }}$ and $5^{\text {th }}$ natural mode. 

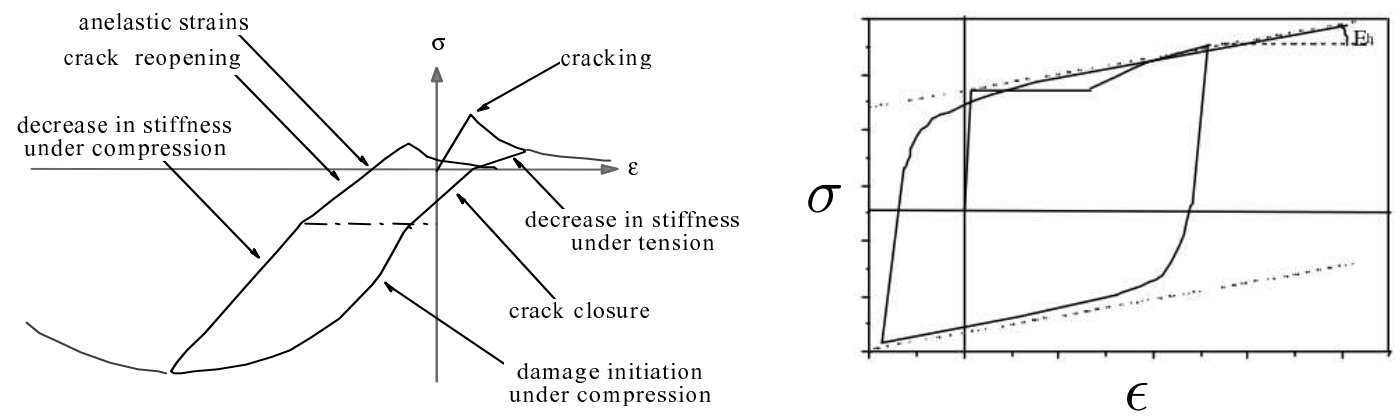

Figure 5. Cyclic response of the La Borderie model for Fongre Cyclic response of the Menegotto-Pinto model for steel.

Table III. Viaduct: material data for concrete and steel constitutive laws.

\begin{tabular}{cccc} 
Concrete parameters & \multicolumn{2}{c}{ Steel parameters } \\
\hline$E$ & $29.4 G P a$ & $E$ & $200 G P a$ \\
$\nu$ & 0.175 & $f_{y}$ & $450 M P a$ \\
$Y_{01}$ & $1000 P a$ & $f_{s u}$ & $710 M P a$ \\
$Y_{02}$ & $0.0001 \mathrm{MPa}$ & $\epsilon_{s h}$ & 0.0060 \\
$A_{1}$ & $7000 \mathrm{MPa}^{-1}$ & $\epsilon_{s u}$ & 0.10 \\
$A_{2}$ & $6.0 \mathrm{MPa}$ & & \\
$B_{1}$ & 1.0 & & \\
$B_{2}$ & 1.3 & & \\
$\beta_{1}$ & $0.5 \mathrm{MPa}$ & \\
$\beta_{2}$ & $-19 \mathrm{MPa}$ & \\
$\sigma_{f}$ & $3.0 \mathrm{MPa}$ & \\
\hline
\end{tabular}

\subsection{Experimental versus numerical results: modal analysis}

Natural frequencies for the structure rigidly constrained at the base are given in Table IV.

Modal deformed shapes of the viaduct are shown in Fig. 7.

Copyright (c) 2002 John Wiley \& Sons, Ltd.

Earthquake Engng Struct. Dyn. 2002; 00:1-6

Prepared using eqeauth.cls 


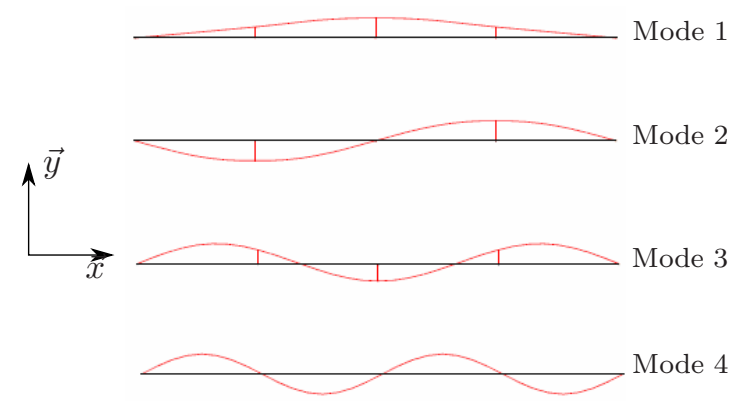

Figure 7. Viaduct: calculated modal shapes.

Table IV. Viaduct: comparisons between experimental and computed modal frequencies.

\begin{tabular}{ccc} 
mode & \multicolumn{2}{c}{ frequency $(\mathrm{Hz})$} \\
\cline { 2 - 3 } & Test & Simulation \\
\hline 1 & 4.2 & 4.2 \\
2 & 6.6 & 6.8 \\
3 & 9.8 & 10.4 \\
4 & 16.1 & 16.8 \\
\hline
\end{tabular}

\subsection{Loading sequence}

The accelerations imposed at the base of the structure derive from a synthetic accelerogram consistent with a $5 \%$ damping response specturm selected according to Eurocode 8 for a soil of class B [8]. Fig. 8(a) shows the comparison between the synthetic spectral response and the design spectra of the Eurocode 8. The synthetic accelerogram is presented in Fig. 8(b). The peak of accelerations is situated at $0.35 \mathrm{~g}$ ("weak" earthquake). A second similar accelerogram (dilated, non represented here), is also imposed at the base of the structure. Its peak of acceleration is equal to $0.7 \mathrm{~g}$ ("strong" earthquake). 

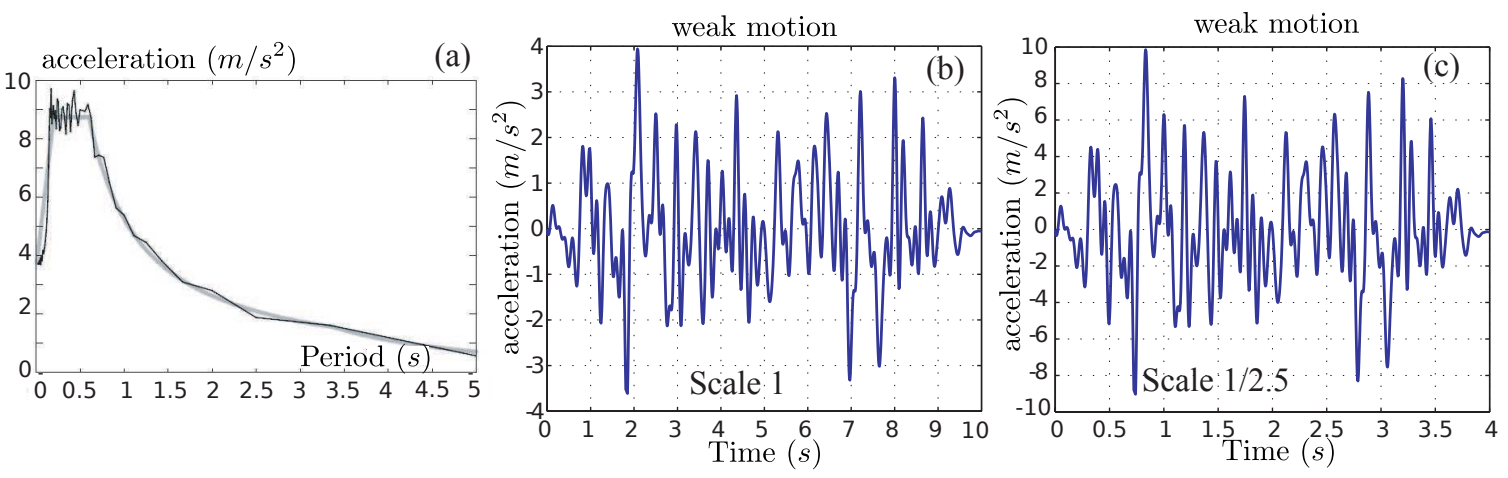

Figure 8. Viaduct: (a) Design spectra coming from Eurocode 8 for a $5 \%$ damping and synthetical accelerogram spectra, (b) weak level earthquake signal for the scale 1 structure and (c) for the scale $1: 2.5$ structure.

It is worth noting that as the small-scale model of the pier is reduced in size by a factor of 2.5, accelerograms have to be modified in order to respect the similitude laws. Accelerations are thus multiplied by 2.5 and time is divided by 2.5 . The weak level earthquake $(0.35 g$ at scale 1) is provided in Fig. 8(c) at scale 1:2.5.

\subsection{Experimental versus numerical results: dynamic analysis}

Figures 9 and 10 show the comparison between the experimental and the numerical results of the dynamic analysis for the fixed structure. The two earthquakes (weak and strong) are considered. The figures show the evolution with time of the shear forces at the base and the lateral displacements at the top of the piers P1, P2 and P3.

One can clearly see that despite the small number of degrees of freedom of the finite element model the non linear behaviour of the viaduct is reproduced quite satisfactorily. Not only the peaks in both directions are well reproduced but the frequency content of the response is correctly matched. 

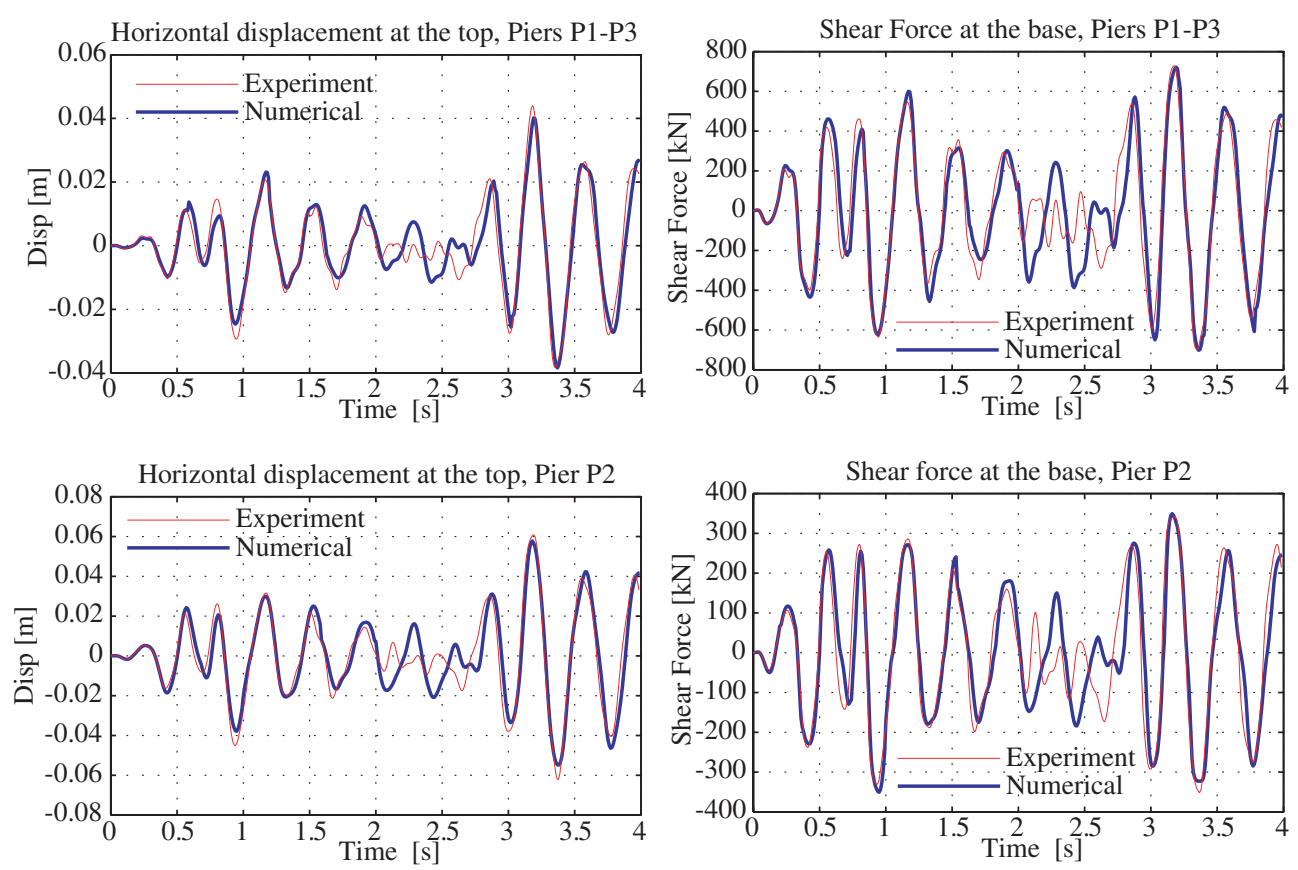

Figure 9. Viaduct: comparison between experimental and numerical displacements and shear forces for the weak level earthquake.

\section{PART II: INFLUENCE OF SOIL-STRUCTURE INTERACTION (SSI)}

In this second part, two modelling strategies are proposed to take into account SSI. The first uses a recently developed macro-element considering material and geometrical non linearities. The second is based on linear elastic springs applied at the base of each pier. Parametric studies taking into account two types of soils and comparisons between the two different modelling strategies are detailed. 

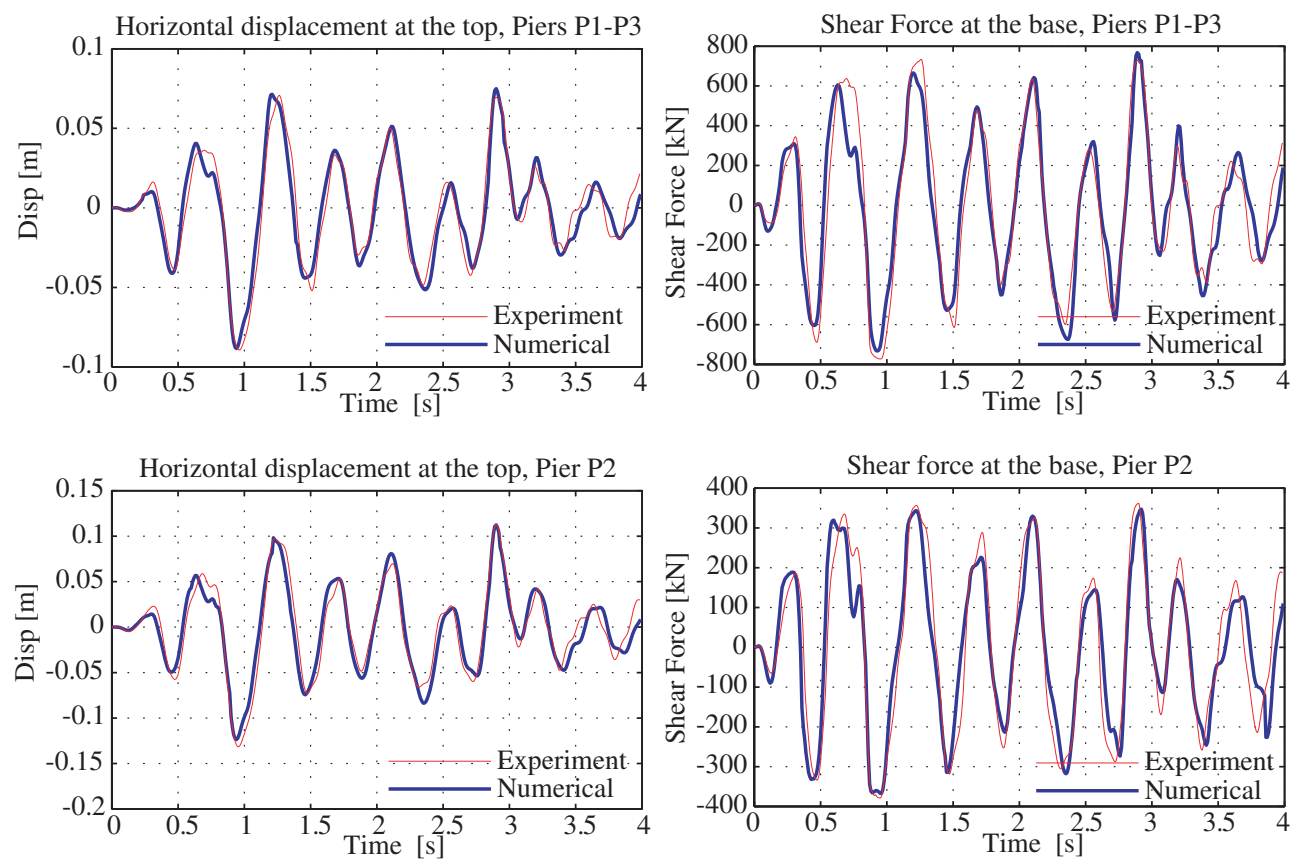

Figure 10. Viaduct: comparison between experimental and numerical displacements and shear forces for the strong earthquake.

\subsection{Description of the macro-element}

The macro-element approach consists in condensing all non linearities into a finite domain and works with generalized variables (forces and displacements) defined at the centre of the foundation. It thus allows a significant reduction of the degrees of freedom. Several macroelements can be found in the literature, e.g., [3], [5], [6], [7], [20], [23]. The macro-element used in this paper takes into account three different mechanisms: elasticity, plasticity of the soil and uplift of the foundation. The total displacement is thus decomposed as a sum of an elastic, plastic and uplift part. Plasticity and uplift are described according to the classical theory of plasticity. 
The general formulation of the macro-element is detailed in [12] for the plasticity model, [13] for the uplift mechanism, [14] for the coupling of the two mechanics and [15] for the dynamic behaviour.

(a)

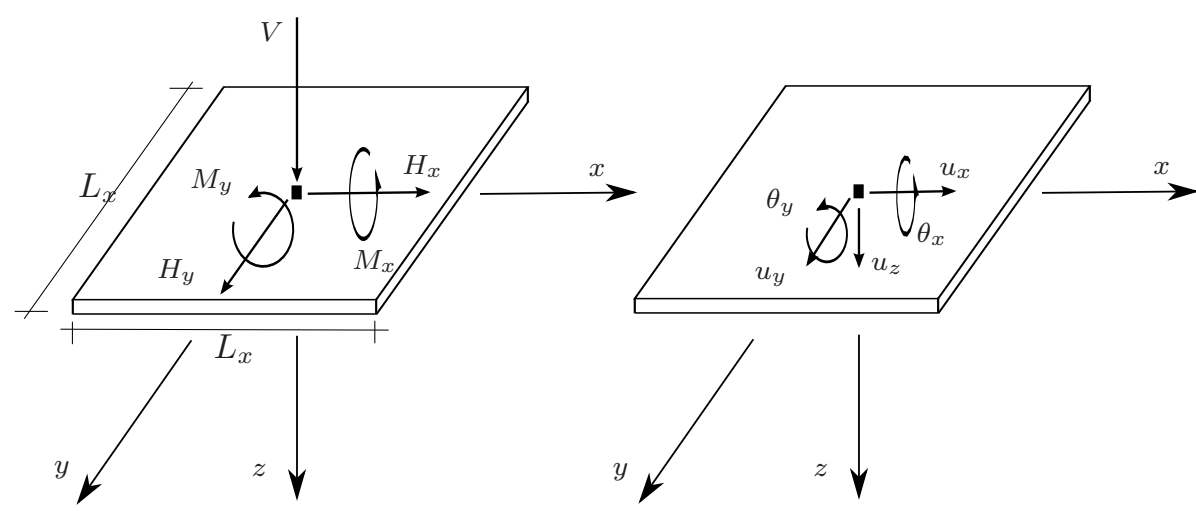

Figure 11. Generalised variables: (a) forces and (b) displacements for a rectangular foundation.

\subsection{Types of soils}

In order to investigate the influence of SSI on the reinforced concrete viaduct, two types of soils are considered, (according to the Eurocode 8 classification [8]): a class B and a class C soil. Both soils are considered purely cohesive. The values of the parameters defining the shape of the failure locus for both soils are given according to [5], and are listed in Table V. See [12] for more details.

\subsection{Geometry of the foundations}

For the class B soil, a rectangular shallow foundation is considered at each pier. The foundation has the dimensions: $L_{x}=4.2 \mathrm{~m}$ and $L_{y}=2.1 \mathrm{~m}$. For the class $\mathrm{C}$ soil and in order to amplify 
Table V. Viaduct - SSI: Characteristics of the soils used for the parametric study.

\begin{tabular}{|c|c|c|c|c|c|c|}
\hline \multirow[t]{2}{*}{ soil } & $\begin{array}{l}\text { Shear } \\
\text { modulus } G_{0}\end{array}$ & $\begin{array}{l}\text { cohesion c } \\
\text { and friction }\end{array}$ & $\begin{array}{l}\text { Stiffness and } \\
\text { damping }\end{array}$ & $\begin{array}{l}\text { ultimate } \\
\text { bearing }\end{array}$ & parameters & $\begin{array}{l}\text { Plastic } \\
\text { cameters }\end{array}$ \\
\hline & velocity $V_{s}$ & angle $\phi$ & {$[10]$} & stress $q_{\max }$ & & \\
\hline Class C & $V_{s}=150 \mathrm{~m} / \mathrm{s}$ & $c_{u}=150 k P a$ & $K_{\theta \theta}=1112.5 \mathrm{MNm} / \mathrm{rad}$ & $q_{\max }=1.1 \mathrm{MPa}$ & $\mathrm{a}$ & 0.32 \\
\hline \multirow[t]{5}{*}{ soil } & $G_{0}=45 M P a$ & $\phi_{u}=0$ & $K_{z z}=298.68 M N / m$ & & $\mathrm{~b}$ & 0.37 \\
\hline & & & $K_{h h}=244.36 M N / m$ & & $\mathrm{c}$ & 0.25 \\
\hline & & & $C_{\theta \theta}=4.34 M N m s / r a d$ & & $\mathrm{~d}$ & 0.55 \\
\hline & & & $C_{z z}=1.17 M N s / m$ & & e & 0.8 \\
\hline & & & $C_{h h}=1.00 M N s / m$ & & $\mathrm{f}$ & 0.8 \\
\hline Class B & $V_{s}=360 \mathrm{~m} / \mathrm{s}$ & $c_{u}=290 k P a$ & $K_{\theta \theta}=144484.1 M N m / r a d$ & $q_{\max }=2.1 M P a$ & $\mathrm{a}$ & 0.32 \\
\hline \multirow[t]{5}{*}{ soil } & $G_{0}=259.2 M P a$ & $\phi_{u}=0$ & $K_{z z}=1845.5 \mathrm{MN} / \mathrm{m}$ & & $\mathrm{b}$ & 0.37 \\
\hline & & & $K_{h h}=2260.2 M N / m$ & & $\mathrm{c}$ & 0.25 \\
\hline & & & $C_{\theta \theta}=23.17 M N m s / r a d$ & & d & 0.55 \\
\hline & & & $C_{z z}=3.61 M N s / m$ & & e & 0.8 \\
\hline & & & $C_{h h}=2.95 M N s / m$ & & $\mathrm{f}$ & 0.8 \\
\hline
\end{tabular}

the influence of SSI a smaller foundation is considered, with $L_{x}=3.2 \mathrm{~m}$ and $L_{y}=1.6 \mathrm{~m}$.

\subsection{Calibration of the linear springs}

For the second model and in order to reproduce the behaviour of the soils seen in Table V, the stiffness of the linear springs have to be calibrated. The following energy criterion is chosen: the stiffness of the springs is such that they accumulate the same energy as the non-linear SSI macro-element (Fig. 12). The energy dissipated by the macro-element in the hysteresis loops 
is not taken into account.

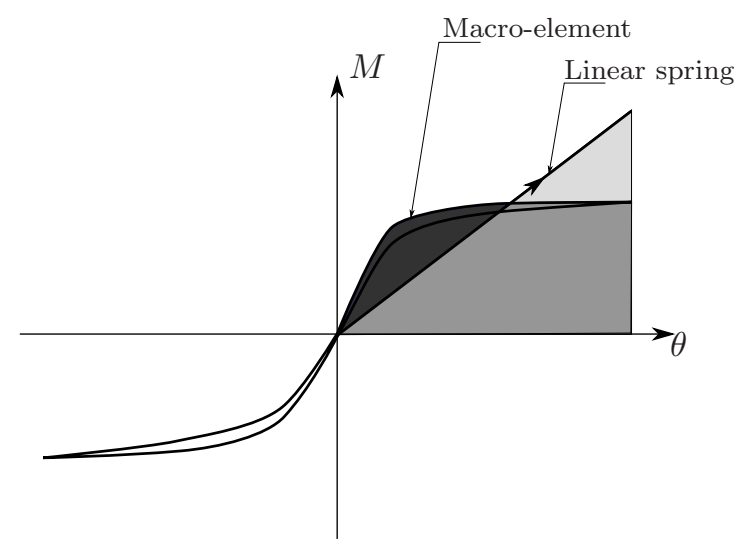

Figure 12. Viaduct - SSI: calibrating the stiffness of the elastic linear springs.

The maximum rotation taken into account for calibrating the stiffness of the linear springs is the maximum rotation for the weak motion for soils B and C. Figure 13 shows the MomentRotation curves for the 2 soils and gives a comparison between the results of the macro-element and the linear springs (EL).

\subsection{Numerical results considering SSI}

The influence of SSI effects on the dynamic response of the viaduct has been evaluated by comparing - for the two soils considered - the predictions obtained by: i) modeling the foundations with the macro-element; ii) modeling the foundations with equivalent linear springs; iii) considering the piers fixed at the base.

Figure 13 shows a comparison between soil B and C in terms of Moment-Rotation curves. It is clear that uplift is the principal mechanism for soil B (S-shape of the loops), whereas plasticity is predominant for soil $\mathrm{C}$ (size of the loops). For both soils, rotations and moments 
are bigger in the case of the strong earthquake.
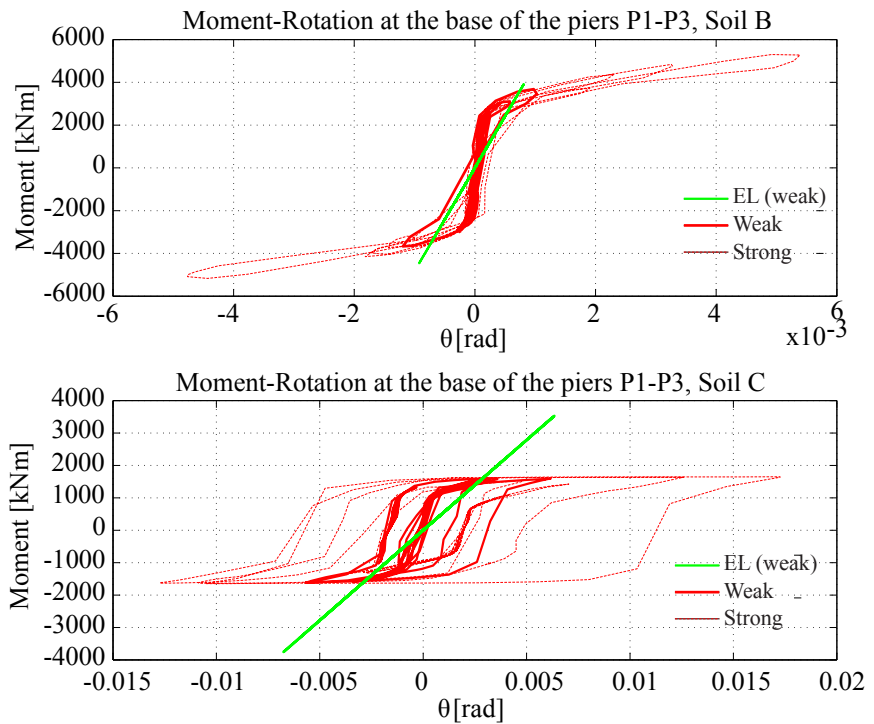

Figure 13. Viaduct - SSI: comparison of the moment-rotations curves for (a) soil B and (b) soil C for the weak and strong motion, considering the macro-element and the linear springs (EL).

3.5.1. SSI - class B soil Only the results for the strong earthquake are presented in this section (Fig. 14). The three types of boundary conditions are denominated as follows: linear springs (EL), macro-element (ME) and fixed (Fixed). Results are similar in terms of internal forces. Nevertheless, maximum displacements at the top of the piers are found significantly increased (multiplied by 1.5) for the cases considering SSI (EL and ME).

For the weak earthquake, the computed response of the structure is the same independently of the assumed boundary conditions (the maximum internal forces and level of damage are similar). Indeed for a stiff soil, damage and non-linearities are concentrated in the lower portion of the piers, close to the foundations. It is the bending strength of the pier that controls the internal forces in the structure. 

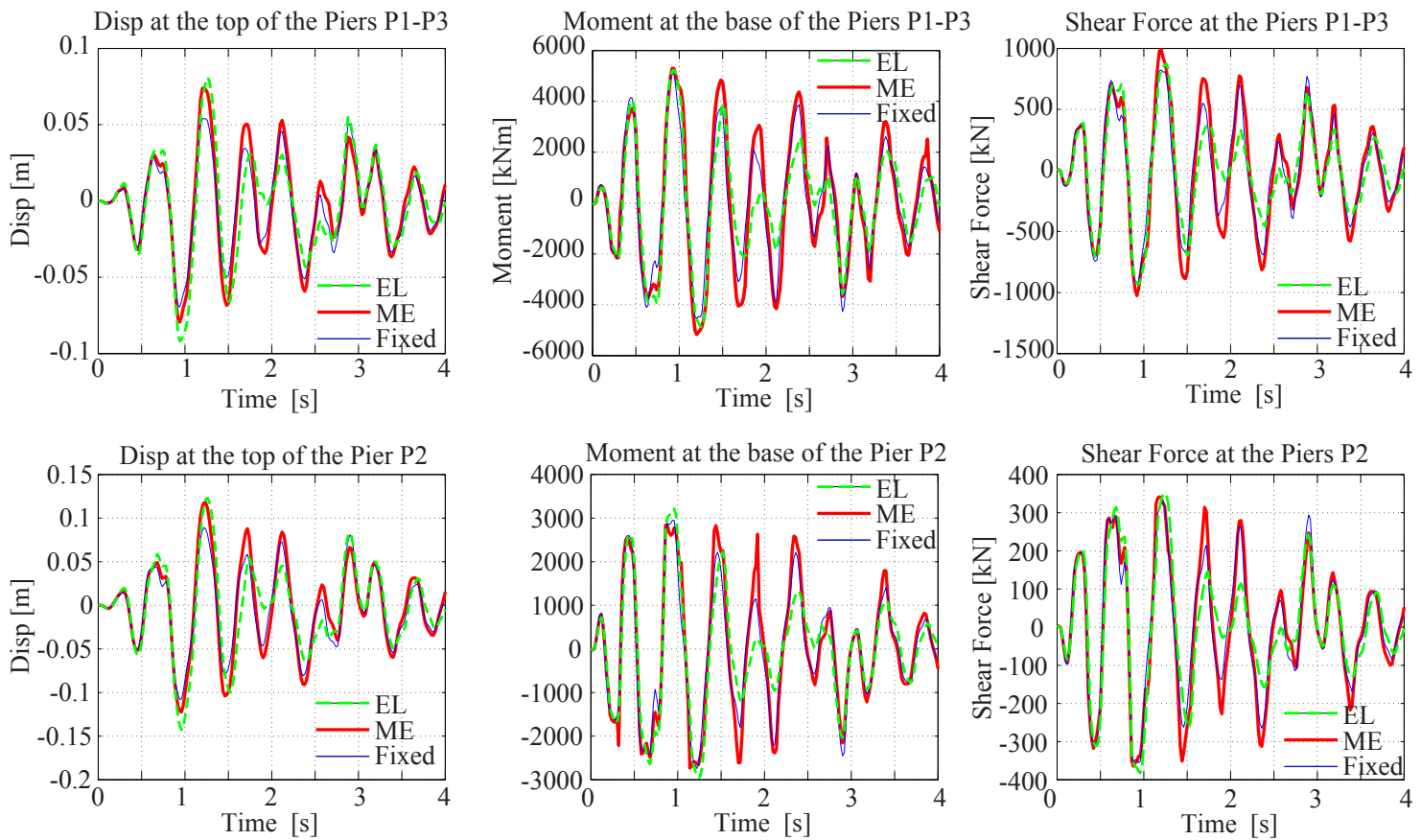

Figure 14. Viaduct - SSI: comparisons of the displacements, moments, shear forces for the strong motion and the class B soil.

3.5.2. SSI - class $C$ soil The results for the weak earthquake are presented in Fig. 15 for the class $\mathrm{C}$ soil. This time, the behaviour of the viaduct is different depending on the the assumed boundary conditions. The displacements are strongly amplified, multiplied by 3 or 4 , for the case of the structure resting on the macro-element and on the linear elastic springs respectively. The results are however more pronounced for the internal forces at the base of the piers (moments and shear forces). In fact, loads on the structure are significantly reduced for the case of the macro-element, due to the bearing moment and force capacity that are reached into the soil. Results obtained with the elastic linear springs have not such limits and can be similar to the ones found for the fixed piers. 

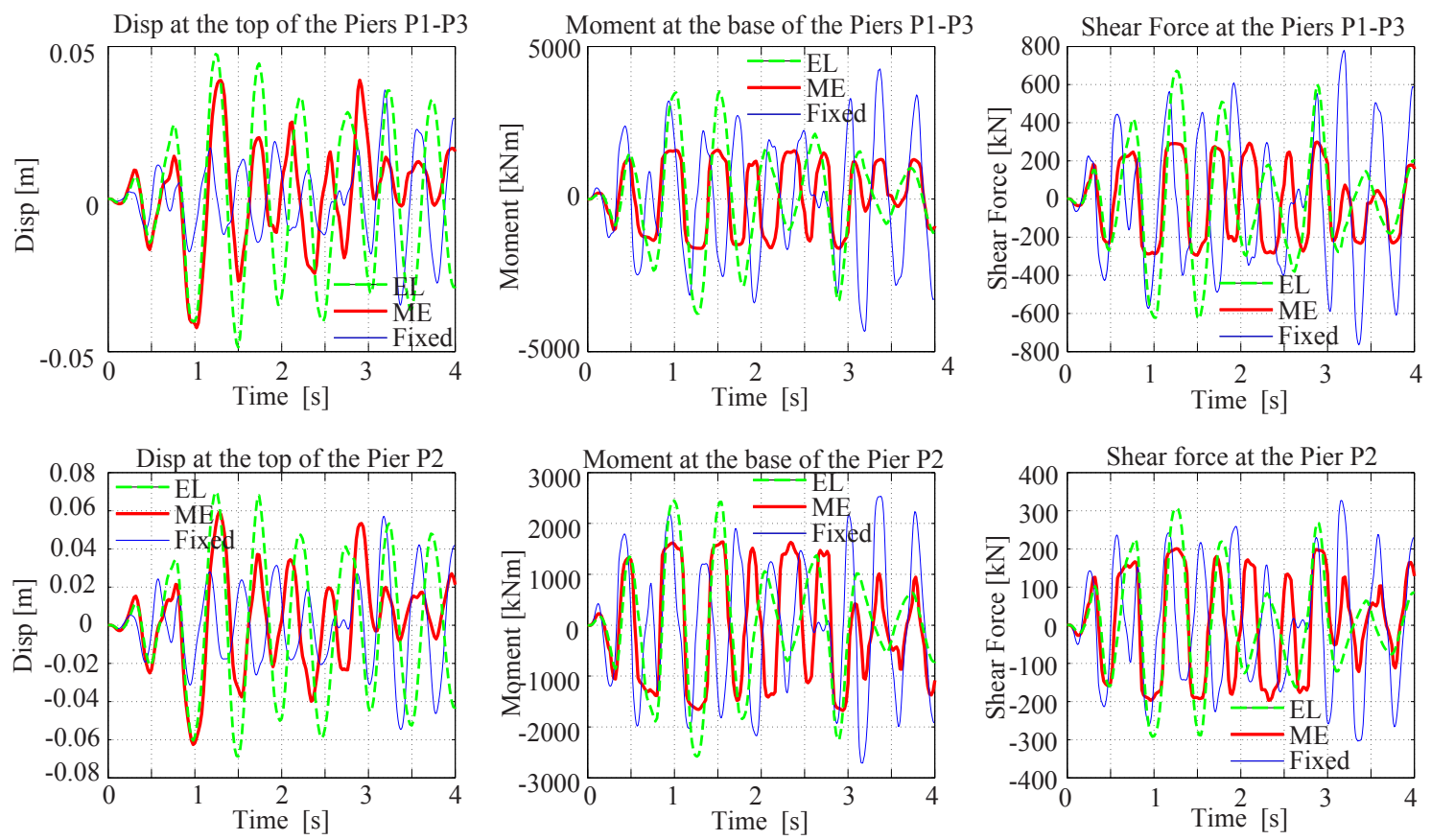

Figure 15. Viaduct - SSI: comparison of the displacements, moments and shear forces for the weak motion and for the class $\mathrm{C}$ soil.

For the strong earthquake, conclusions about the computed response of the structure are similar. Forces are limited by the bearing capacity of the foundation and displacements are amplified compared to the weak motion.

\section{CONCLUSIONS}

In this work we propose a new simplified numerical strategy to analyse dynamic Soil-Structure Interaction (SSI) problems, based on the macro-element approach. The structural part of the numerical model, employing Timoshenko multifiber beam elements with complex nonlinear 
constitutive laws, is validated by comparing the predicted response with the experimental results obtained on a small-scale, three-piers reinforced concrete viaduct, tested pseudodynamically at the ELSA laboratory.

Two groups of numerical simulations are presented: In the first part of the work, the structural part of the numerical model, employing Timoshenko multifiber beam elements with complex nonlinear constitutive laws, is validated by comparing the predicted response with the experimental results obtained on the reinforced concrete viaduct at the ELSA laboratory. In the FE simulations, the piers are fixed at the base and no SSI effect is considered. In the second part of the work, the effects of SSI interaction have been evaluated considering two different types of soils (class B and C). The influence of SSI is quantified by modelling the foundation-soil system with a single kinematic hardening elastoplastic macro-element, placed at the bottom of each pier. It is found that SSI isolates the structure as global forces and damage are significantly reduced in this case. Finally, comparison with an engineering approach based on linear elastic springs with an equivalent elastic stiffness calibrated using an energy criterion shows clearly the advantages of the new macro-element. More specifically:

- for a class $\mathrm{C}$ soil (of poor mechanical properties), internal forces at the base of the piers are smaller compared to the ones provided considering the piers fixed at the base. The displacements at the top of the structure are strongly amplified (multiplied by 4 ).

- for a class B soil (of good mechanical properties), non-linearities are concentrated principally at the base of each pier. In other words, the resisting moment of the pier section controls the behaviour of the structure. The maximum structural strength of the pier is reached before the collapse of the foundation-soil system. The response of the system is similar as if the piers were fixed at the base, except for the displacements which 
are significantly amplified (multiplied by 2).

Finally, the limits of the classical engineering approach based on elastic linear springs are evident. The results obtained with this approach are conservative (particularly for the case of a class $\mathrm{C}$ soil). Internal forces and displacements are higher than the ones obtained using the macro-element approach, which allows a more appropriate description of the non-linear behaviour of the foundation-soil system. Moreover, in spite of the appealing simplicity of this approach, the a-priori calibration of the spring constants remains a quite difficult task.

Based on the results obtained in this work, it appears now possible to use the macro-element approach in both research and current design practice, to investigate numerically the behaviour of a wider variety of configurations that is practically impossible to study experimentally. However, more experimental results under dynamic loadings are crucially needed in order to validate the performance of the macro-element.

\section{ACKNOWLEDGEMENTS}

Part of this work has been done within the European Contract LESSLOSS, Risk Mitigation for Earthquakes and Landslides, Sixth Framework Programme, (Project No.: GOCE-CT-2003-505488), http://www.lessloss.org.

\section{REFERENCES}

1. Botrugno L. Influenza del modello di interazione terreno-struttura sul comportamento dinamico di un ponte in c.a. Università degli Studi di Perugia, 2008.

2. Cast3M. Official web site: http://www-cast3m.cea.fr/cast3m/index.jsp

3. Chatzigogos CT, Pecker A, Salençon J. Macroelement modeling of shallow foundations. Soil Dynamics and Earthquake Engineering 2009; 29(5):765-781. 
4. Collin F. Couplages Thermo-hydro-mécaniques dans les sols et les roches tendres partiellement saturés. PhD Thesis, Université de Liège, 2003.

5. Crémer C. Modélisation du comportement non linéaire des fondations superficielles sous séismes. PhD Thesis, LMT Cachan - ENS Cachan, France, 2001.

6. Crémer C, Pecker A, Davenne L. Cyclic macro-element for soil-structure interaction: material and geometrical non-linearities. International Journal for Numerical and Analytical Methods in Geomechanics $2001 ; 25(13): 1257-1284$.

7. Crémer C, Pecker A, Davenne L. Modelling of nonlinear dynamic behaviour of a shallow strip foundation with macro-element. Journal of Earthquake Engineering 2002; 6(2):175-211.

8. EC8. NF P 06 030-1, NF EN 1998-1, Eurocode 8 : Calcul des structures pour leur résistance aux séismes. Partie 1 : Règles générales, actions sismiques et règles pour les bâtiments, AFNOR, Septembre 2005.

9. Filippou FC, Constantinides M. FedeasLab Getting Started Guide And Simulations Examples. Dpt of civil and env. Engng. UC Berkeley, 2004.

10. Gazetas G. Foundations vibrations. Foundation Engineering Handbook, Chapter 15. Fang H-Y (ed.), van Nostrand Reinhold: New York, 1991.

11. Grange S. Modélisation simplifiée 3D de l'interaction sol-structure: application au génie parasismique. PhD Thesis, laboratoire 3S-R, INP Grenoble, France, 2008. http://tel.archives-ouvertes.fr/tel-00306842/fr

12. Grange S, Kotronis P, and Mazars J. A macro-element for a circular foundation to simulate 3D soilstructure interaction. International Journal for Numerical and Analytical Methods in Geomechanics, 2008; 32(10):1205-1227.

13. Grange S, Kotronis P, and Mazars J. A macro-element for a shallow foundation to simulate Soil-Structure Interaction considering uplift. C. R. Mécanique 2008; 336(11-12):856-862.

14. Grange S, Kotronis P, and Mazars J. A macro-element to simulate 3D soil-structure interaction considering plasticity and uplift. International Journal of Solids and Structures, 2009; 46(20):3651-3663.

15. Grange S, Kotronis P, and Mazars J. A macro-element to simulate dynamic soil-structure interaction. Engineering Structures, 2009; 31(2009):3034-3046.

16. Kotronis P, Mazars J. Simplified modelling strategies to simulate the dynamic behaviour of r/c walls. Journal of Earthquake Engineering 2005; 9(2):285-306.

17. La Borderie C. Phénomènes unilatéraux dans un matériau endommageable: modélisation et application l'analyse des structures en béton. PhD thesis, Université Paris 6, 1991.

18. Mazars J, Kotronis P, Ragueneau F, and Casaux G. Using multifiber beams to account for shear and torsion. 
applications to concrete structural elements. Computer Methods in Applied Mechanics and Engineering $2006 ; \mathbf{1 9 5}(52): 7264-7281$.

19. Menegotto M, Pinto P. Method of analysis of cyclically loaded reinforced concrete plane frames including changes in geometry and non-elastic behaviour of elements under combined normal force and bending. In IABSE Symposium on resistance and ultimate deformability of structures acted on by well-defined repeated loads, final report, Lisbon, 328p, 1973.

20. Nova R, Montrasio L. Settlements of shallow foundations on sand. Géotechnique 1991; 41(2):243-256.

21. Pecker A. Analytical formulae for the seismic bearing capacity of shallow strip foundations. In Seismic Behavior of Ground and Geotechnical Structures, Seco e Pinto (ed.). Balkema: Rotterdam, 1997; $261-268$.

22. Pinto A.V., Verzeletti G, Pegon P., Magonette G., Negro P., Guedes J. Pseudo Dynamic Testing of LargeScale R/C Bridges. In HMC Grant Holder, Report EUR 16378 EN , 1996;

23. Salciarini D, Tamagnini C. A hypoplastic macroelement model for shallow foundations under monotonic and cyclic loads. Acta Geotechnica 2009; 4(3):163-176.

24. Simo JC, Hughes TJR. Computational Inelasticity, Mechanics and materials, Springer Interdisciplinary applied mathematics, vol.7, 1998. 